\title{
Analysis of Problems of Science Teachers in Learning of Prakarya for the Mentoring Activities of Applied Science in Sijunjung Regency
}

\author{
R Afrizon ${ }^{1}$, H Hidayati ${ }^{1}$, R Yogica ${ }^{2}$ \\ ${ }^{1}$ Jurusan Fisika, Universitas Negeri Padang, Jl. Prof. Dr. Hamka, Air Tawar, Padang 25131, Indonesia \\ ${ }^{2}$ Jurusan Biologi, Universitas Negeri Padang, Jl. Prof. Dr. Hamka, Air Tawar, Padang 25131, Indonesia \\ * afrizon@fmipa.unp.ac.id
}

Diterima 17 September 2019, Disetujui 25 November 2019, Dipublikasikan 30 November 2019

\begin{abstract}
Natural science teachers at Sijunjung Regency Junior High School must teach science and prakarya subjects in meeting the teaching load in their respective schools. $65 \%$ of the science teachers at the Sijunjung district junior secondary school teach prakarya subjects. Provision of mentoring activities can be used as a solution that is expected to motivate teachers to continue to improve their competence. Before the service community activities are carried out then disseminate questionare to see the initial conditions in more detail in the learning of prakarya so that it can be used as a reference in the implementation of applied science mentoring activities in prakarya learning. The questionnaire was distributed using the Gutman scale. The distribution of the questionnaire was carried out on July 13, 2019 before the mentoring activities began. Analysis of the data used is descriptive data analysis. The analysis showed that the junior high school science teachers in Sijunjung Regency were still not professional in teaching crafts at school. This is due to the still lack of application of science / science in learning of prakarya. Prakarya subjects have four material aspects, namely: crafts, engineering, cultivation, and processing. The material aspect of crafts is more dominantly taught by science teachers in prakarya subjects even though this material aspect is more appropriate to be taught by arts / culture teachers. In addition, there are still very few natural science teachers who are able to compile prakarya teaching materials. Therefore, the results of this initial condition analysis can be used as a reference in the implementation of applied natural science mentoring activities in prakarya learning so that it suits the needs.
\end{abstract}

Keywords - Community Service, Applied Natural Science, Prakarya, Sijunjung Regency

This is an open access article distributed under the Creative Commons 4.0 Attribution License, which permits unrestricted use, distribution, and reproduction in any medium, provided the original work is properly cited. (C)2017 by author and Universitas Negeri Padang.

\section{Pendahuluan}

Sijunjung merupakan salah satu kabupaten yang terletak di Provinsi Sumatera Barat. Kabupaten ini berbatasan langsung dengan kabupaten Kuantan Singingi, Riau di sebelah timur, kabupaten Tanah Datar dan kota Sawahlunto di sebelah barat, serta kabupaten Solok dan kabupaten Dharmasraya di sebelah selatan. Kabupaten sijunjung memiliki luas $3.130,80 \mathrm{~km}^{2}$ dengan jumlah penduduk lebih dari 202.000 jiwa seperti terlihat pada Gambar 1 . Kabupaten Sijunjung yang terdiri dari 8 kecamatan yang salah satunya adalah kecamatan kamang baru.

Kegiatan utama masyarakat di kecamatan kamang baru lebih banyak terkait bidang perkebunan dan pertanian. Komoditas perkebunan yang banyak dibudidayakan oleh masyarakat kamang baru adalah kelapa sawit dengan produksi $99,36 \%$ produksi di kabupaten sijunjung(https://www.sijunjung.go.id/v2/potensidaerah/potensi-perkebunan/). Dari segi pertanian, tanaman palawija sudah tersebar diseluruh kecamatan dengan jenis tanaman berupa jagung, kacang hijau, ubi kayu dan kacang tanah. Khusus 
untuk kacang hijau, jagung dan kacang tanah masih perlu mendapat perhatian yang lebih intensif (https://www.sijunjung.go.id/v2/potensidaerah/potensi-pertanian/). Kondisi ini dapat menggambarkan bahwa sektor perkebunan dan pertanian memberikan andil cukup besar dalam perekonomian masyarakat yang tinggal di daerah ini.

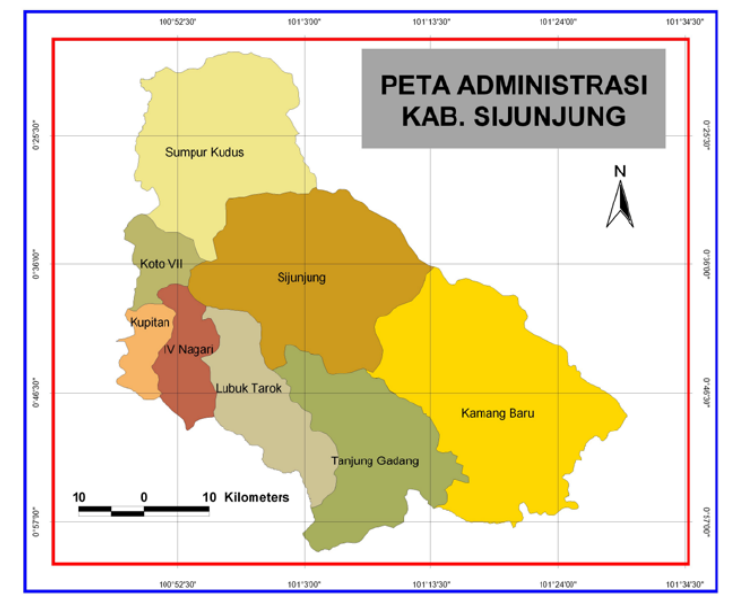

Gambar 1. Peta Administrasi Kabupaten Sijunjung

Mata pelajaran prakarya adalah mata pelajaran di tingkat SMP/MTs yang membekali peserta didik berkaitan dengan wawasan kewirausahaan agar dapat mandiri secara ekonomi dan diarahkan pada pengembangan produk sesuai potensi daerah dengan menggunakan teknologi tepat guna skala home industry. MGMP IPA SMP kabupaten Sijunjung merupakan wadah perkumpulan guruguru IPA SMP yang berguna untuk membantu guru dalam memecahkan dan menyelesaikan dalam pembelajaran. Hasil wawancara dengan ketua MGMP menunjukkan bahwa $65 \%$ guruguru IPA SMP kabupaten sijunjung mengajar mata pelajaran prakarya. Guru-guru IPA SMP Kabupaten Sijunjung harus mengampu mata pelajaran IPA dan prakarya dalam memenuhi beban mengajar di sekolah masing-masing. Oleh karena itu, perlu dilakukan analisis kebutuhan yang bertujuan untuk menganalisis kondisi awal pembelajaran prakarya sehingga dapat digunakan sebagai rujukan dalam pelaksanaan kegiatan pendampingan sains terapan dalam pembelajaran prakarya.

\section{Solusi/Teknologi}

Gambaran iptek yang akan ditransfer kepada mitra berkaitan dengan aspek pengetahuan dan teknologi. Dari segi aspek pengetahuan, guruguru IPA kabupaten Sijunjung akan diberikan pengetahuan terkait sains/IPA terapan secara umum berupa konstruksi atap rumah gadang mampu bertahan dari masalah kebocoran dan terpaan angin (hasil penelitian tim pengusul), pengenalan jenis-jenis sistem hidroponik, pengenalan biodiesel, model sains terapan dan cara pembuatannya, teknis penyusunan LKS. LKS yang akan dirancang pada program PKM ini adalah LKS prakarya yang memuat sains terapan. Struktur LKS yang disusun sesuai dengan petunjuk pengembangan bahan ajar. LKS merupakan panduan bagi siswa untuk melakukan sesuatu yang menghasilkan kemampuan berpikir. Guru dalam merancang LKS prakarya harus dapat mengaitkan dengan lingkungan, sumber daya alam, dan energi di sekitarnya, kearifan lokal dan konteks global. Hal ini berdampak kepada siswa agar dapat memelihara dan memanfaatkan lingkungannya sebagai sumber belajar.

Disamping aspek pengetahuan, tim pengusul juga akan mentransfer aspek teknologi yaitu cara mendesaian dan praktik pembuatan sains terapan berupa teknologi hidroponik dan biodiesel. Biodiesel merupakan bahan bakar alternatif untuk mesin diesel yang terbuat dari minyak sayur dan/atau lemak hewani. Biodiesel yang akan ditransfer teknologi nantinya menggunakan bahan baku minyak jelantah/CPO. Biodiesel berasal dari bahan organik yang terbarukan dan telah ditunjukkan mengurangi emisi berbahaya tertentu ketika dibakar dibandingkan diesel konvensional.

Salah satu tipe sistem hidroponik yang dijadikan sebagai sains terapan dalam mata pelajaran prakarya adalah sistem sumbu (wick system). Sistem sumbu adalah sistem hidroponik yang paling sederhana yakni dengan memanfaatkan sumbu yang dihubungkan antara larutan nutrisi pada bak penampung dengan media tanam. Sistem sumbu ini memanfaatkan daya kapilaritas sumbu sehingga larutan nutrisi dapat mencapai akar tanaman. Kelebihan dari sistem sumbu adalah tidak memerlukan media 
tanam yang terlalu besar. Sistem hidroponik tipe sistem sumbu dapat dilihat pada Gambar 2.

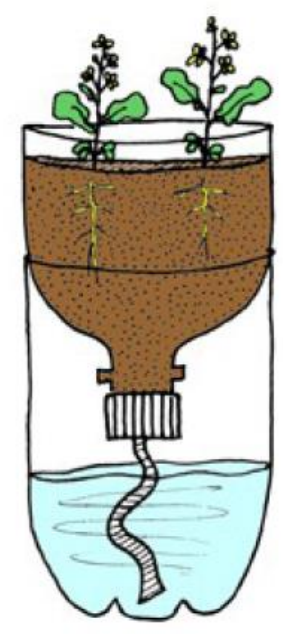

Gambar 2. Sistem Hidroponik Sistem Sumbu (Wick System) [1]

Kegiatan yang dilaksanakan bentuk kegiatan pendampingan ini mengunakan metode yang terdiri dari beberapa tahapan. Tahap awal yang akan dilaksanakan adalah tahap orientasi dan diskusi untuk mengidentifikasi potensi daerah dan menyusun rencana, jadwal dan teknis pelaksanaan kegiatan. Tahap kedua berupa tahap persiapan kegiatan yang meliputi urusan perijinan, pembuatan model sains terapan di laboratorium, instrumen pengumpul data, template Lembar Kerja Siswa (LKS), dan menyusun bahan ajar/panduan pembuatan sains terapan. Tahap ketiga merupakan tahap pendampingan 1 (in) Sebelum kegiatan pendampingan 1 (in) dilaksananakan, maka dilihat terlebih dahulu kondisi awal guru-guru IPA dalam pembelajaran prakarya menggunakan angket. Jumlah guru IPA yang menjadi responden adalah sebanyak 20 orang yang guru IPA yang mengampu mata pelajaran prakarya kelas VII, VIII, dan IX.

Data dikumpulkan dengan menggunakan kuesioner menggunakan skala Gutman. Pengumpulan data yang dilaksanakan tanggal 13 Juli 2019 sebelum kegiatan pendampingan dilaksanakan. Teknik analisis data yang digunakan adalah analisis data deskriptif dengan percent agreement yang merupakan cara sederhana mengukur persetujuan [2].

\section{Hasil dan Diskusi}

Tim pengabdi telah berhasil mengumpulkan data yang berkaitan dengan kondisi awal mitra peserta pengabdian masyarakat. Respon mitra berkaitan dengan kemampuan guru IPA dalam: 1) pelaksanaan pembelajaran prakarya sesuai aspeknya, 2) penerapan sains terapan dalam pembelajaran prakarya, dan 3) penyusunan dan penggunaan LKS dalam pembelajaran prakarya.

\section{Komponen Pelaksanaan Prakarya sesuai Aspek Materinya}

Analisis angket terkait pelaksanaan pembelajaran prakarya yang telah dilaksanakan seperti terlihat pada Gambar 3.

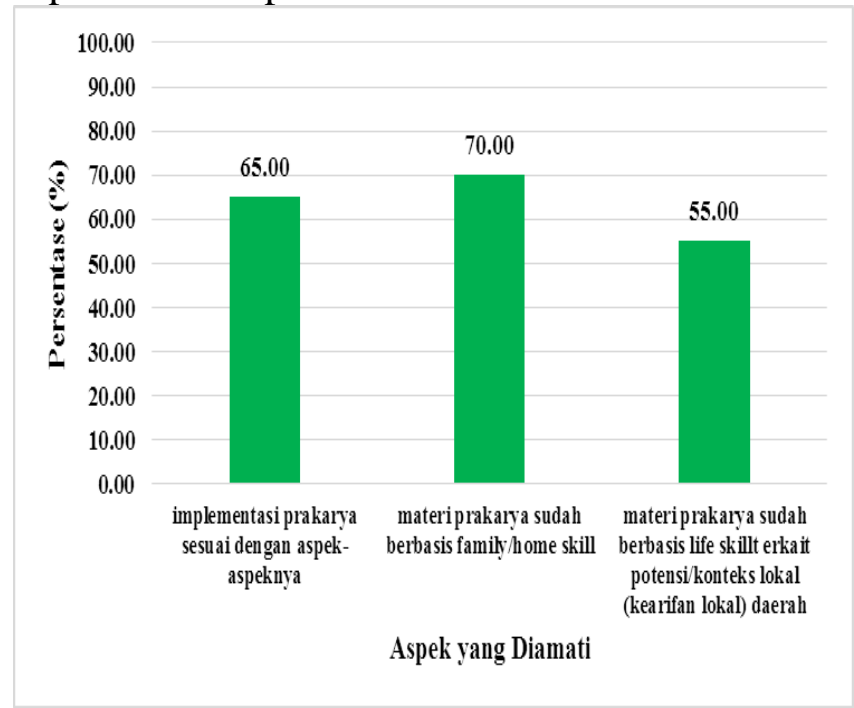

Gambar 3. Kondisi Awal Guru terkait

Pelaksanaan Pembelajaran Prakarya

Gambar 3 menunjukkan bahwa 70\% guru sudah mengajarkan prakarya berbasis family/home skill. Selain itu, 55\% guru-guru sudah mengajarkan materi prakarya sudah berbasis life skill yang terkait dengan potensi dan kearifan lokal daerah. $65 \%$ guru-guru IPA telah mencoba mengimplementasikan mata pelajaran prakarya sesuai dengan aspek materinya yang tercantum pada kurikulum 2013. Adapun pelaksanaan aspek materi dalam pembelajaran prakarya seperti terlihat pada Gambar 4. 


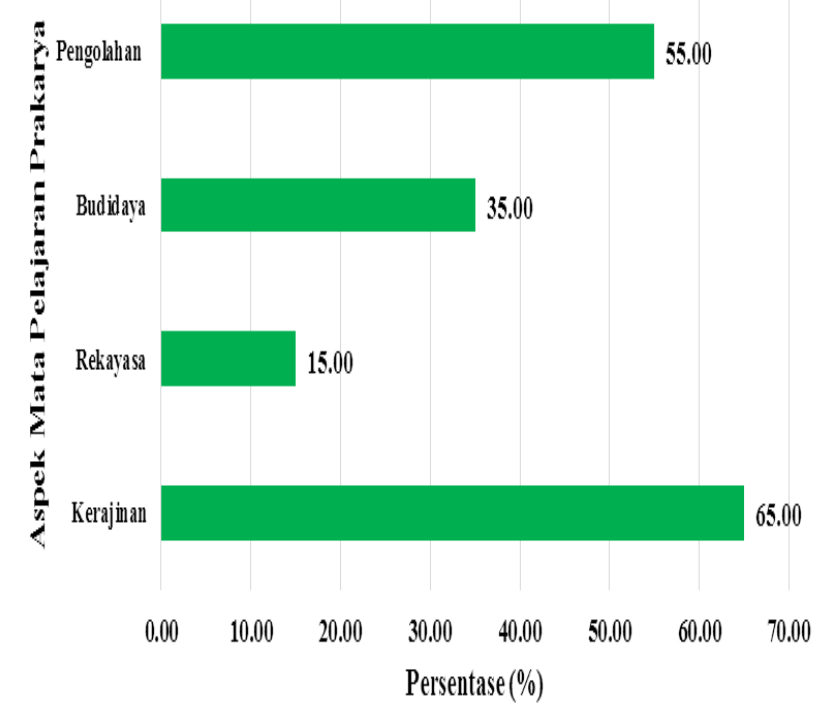

Gambar 4. Aspek Materi Prakarya yang Diajarkan oleh Guru IPA

Gambar 4 menunjukkan bahwa $65 \%$ guru-guru IPA kabupaten sijunjung mengajarkan aspek kerajinan dalam mata pelajaran prakarya. Aspek Kerajinan yang diajarkan berupa 1) kerajinan berbasis media campuran, 2) kerajinan bahan serat, 3) membuat pot dari stik es, membuat kerajinan tikar, membuat kerajinan dari bahan keras, kerajinan limbah organik dan anorganik, kerajinan media campuran, membuat baju dari plastik, membuat dompet dari tempat pensil. $15 \%$ guru mengajarkan aspek rekayasa, misalnya: pembuatan alat penjernihan air, lampu tidur, miniatur jembatan. 35\% guru mengajarkan aspek budidaya, misalnya: budidaya ikan hias, budidaya tanaman obat, pembuatan aquarium mini, tanaman obat. 55\% guru mengajarkan aspek pengolahan, contohnya adalah: memasak, bahan pangan sayuran, mengolah bakso, bahan makanan dari bahan dasar ikan, bahan makanan dari ubi, buah segar, bahan makanan dari daging. Hal ini menunjukkan bahwa aspek materi kerajinan lebih dominan diajarkan oleh guru IPA padahal aspek materi ini lebih tepat diajarkan oleh guru yang memiliki latar belakang pendidikan seni/budaya/keterampilan pada mata pelajaran prakarya.

\section{Komponen Penerapan Sains IPA Terapan dalam Pembelajaran Prakarya}

Penerapan sains/IPA dalam pembelajaran prakarya dan pelatihan yang diikuti oleh guruguru IPA dapat dilihat pada Gambar 5.

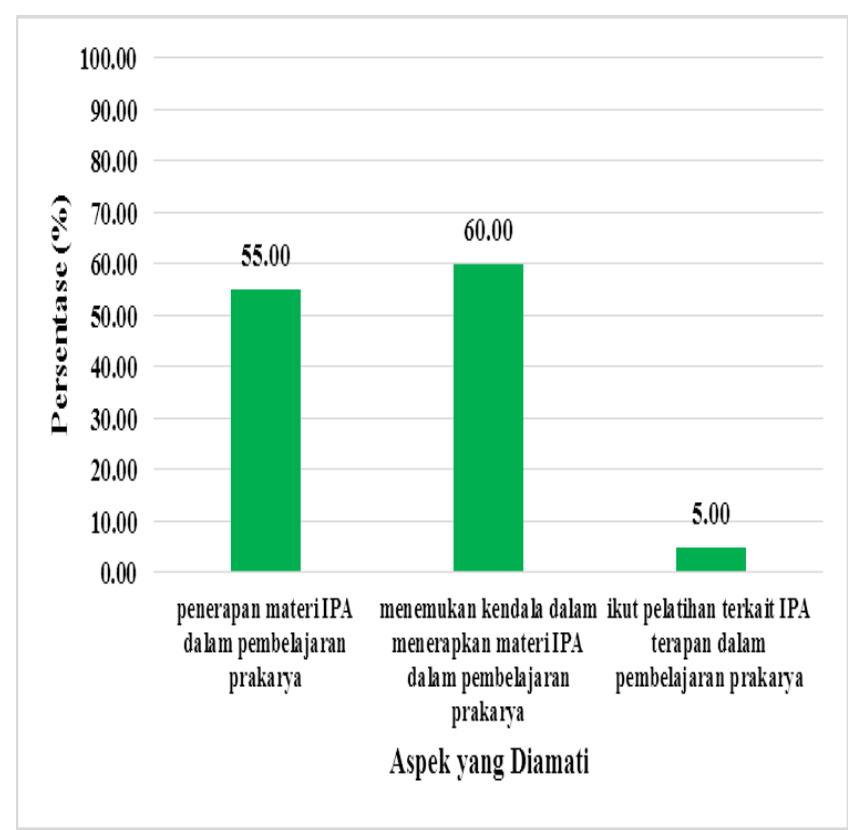

Gambar 5. Kondisi Awal Guru IPA terkait penerapan IPA dalam pembelajaran prakarya

Gambar 5 menunjukkan bahwa $55 \%$ guru sudah menerapkan materi IPA dalam pembelajaran prakarya dimana $60 \%$ guru IPA memiliki kendala untuk menerapkan materi IPA dalam pembelajaran prakarya. Beberapa hal yang menjadi kendala diantaranya adalah kurangnya referensi, masih kurangnya pengetahuan, dan masih kurangnya pengalaman guru mengenai prakarya. Selain itu, hanya 5\% guru yang pernah mengikuti pelatihan terkait IPA terapan dalam pembelajaran prakarya.

\section{Komponen penyusunan dan penggunaan LKS dalam Pembelajaran Prakarya}

Hasil analisis angket terkait komponen penyusunan dan LKS dalam pembelajaran prakarya seperti terlihat pada Gambar 6. 


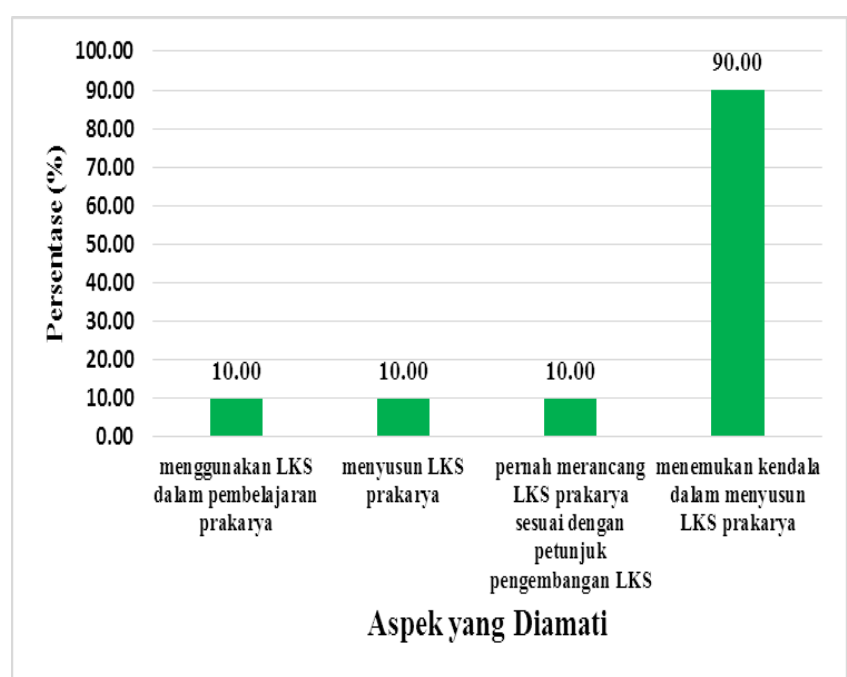

Gambar 6. Kondisi Awal Guru terkait Rancangan pembelajaran Prakarya

Gambar 6 menunjukkan bahwa hanya $10 \%$ guru-guru IPA yang menyusun dan menggunakan LKS. LKS yang disusun telah sesuai petunjuk pengembangan tetapi $90 \%$ guru masih memiliki kendala dalam menyusun LKS prakarya. Faktorfaktor yang menjadi penyebab guru kesulitan dalam menyusun LKS prakarya, diantaranya: 1) kurangnya referensi, 2) kurangnya pengalaman dalam mengajarkan prakarya, dan 3) belum memiliki keahlian dalam mengajarkan prakarya. Jadi, dapat dikatakan kompetensi pedagogik guru-guru IPA kabupaten Sijunjung.

Hasil analisis menunjukkan bahwa kompetensi professional dan pedagogik guru IPA kabupaten sijunjung dalam pembelajaran prakarya belum optimal. Belum optimalnya kompetensi profesional guru IPA yang ditandai dengan kurangnya penerapan sains terapan dalam pembelajaran prakarya. Kontribusi sains/IPA untuk diterapkan dalam pembelajaran prakarya sangat besar yaitu $75 \%$ dari keseluruhan aspek materi prakarya sehingga guru-guru IPA dapat melaksanakan pembelajaran prakarya secara optimal.

Beberapa contoh sains/IPA terapan adalah berikut ini. Materi rekayasa dapat berupa rekayasa penyambungan balok kayu untuk membuat susunan (konstruksi) kerangka atap rumah, harus dilakukan dengan prinsip ketepatan agar susunan rumah tidak mudah runtuh [3]. Meskipun, atap rumah gadang terbuat dari ijuk tapi tetap bertahan dari masalah kebocoran dan terpaan angin. Hal ini disebabkan karena desain atap rumah gadang memiliki beberapa fungsi secara fisis, diantaranya: (1) memperbesar kecepatan aliran air hujan yang jatuh ke atap, (2) memperkecil momentum pada atap, (3) mengurai gaya tekan angin ke segala arah sehingga angin tidak terperangkap pada atap rumah gadang, (4) terciptanya gaya adhesi abu dapurdengan ijuk yang bagus (ijuk lapisan dalam), dan (5) air yang mengendap pada ijuk yang jelek (ijuk lapisan luar) akan naik kembali ke permukaan atap melalui mekanisme kapilaritas [4].

Aspek materi budidaya dengan substansi yang dipelajari berupa tanaman, ternak dan ikan. Teknologi budidaya memiliki manfaat edukatif berupa pembinaan perasaan, pembinaan kemampuan memahami pertumbuhan dan menyatukan dengan alam (ecosystem) agar menjadi siswa yang berpikir sistematis berdasarkan potensi kearifan lokal [3]. Salah satu contoh teknologi budidaya adalah sistem hidroponik. Hydroponics is method of growing plants using mineral Nutrients solutions in Water without soil. Hydroponics technique is best way to grow vegetables, fruits, plants without soil. Hydroponics can be grown outdoors, indoors even in small space. Hydroponic allow for crop to grow in area where growing traditionally has been problem and the place where soil is poor and where water is minimumwhere farm land is too expensive [5].

Aspek materi pengolahan berupa proses pengolahan mencakup proses transformasi (perubahan bentuk) dari bahan mentah menjadi produk olahan yang melibatkan proses-proses fisik, kimia, maupun mikrobiologis. Salah satu contoh teknologi pengolahan adalah pembuatan biodiesel. Biodiesel yang akan diajarkan menggunakan bahan baku minyak jelantah. Langkah-langkah pembuatan biodiesel menggunakan bahan baku minyak jelantah [6].

Pendampingan terkait bahan ajar berupa LKS prakarya yang memuat sains terapan dapat mengoptimalkan kemampuan pedagogik guru dalam pembelajaran prakarya. Guru yang merancang LKS juga harus mempertimbangkan tujuan mata pelajaran prakarya. Tujuan mata pelajaran prakarya adalah membekali peserta didik untuk: 1) menemukan, membuat, merancang ulang dan mengembangkan produk prakarya berupa: kerajinan, rekayasa, budidaya 
dan pengolahan melalui kegiatan mengidentifikasi, memecahkan masalah, merancang, membuat, memanfaatkan, menguji, mengevaluasi, dan mengembangkan produk yang bermanfaat dalam kehidupan sehari-hari; 2) menemukan atau mengemukakan gagasan atau ide-ide yang mampu memunculkan bakat siswa, terutama pada jenjang pendidikan dasar; 3) mengembangkan kreatifitas melalui: mencipta, merancang, memodifikasi, dan merekonstruksi berdasarkan pendidikan teknologi dasar, kewirausahaan dan kearifan lokal, 4) melatih kepekaan siswa terhadap perkembangan ilmu pengetahuan, teknologi dan seni untuk menjadi inovator dengan mengembangkan: rasa ingin tahu, rasa kepedulian, rasa keindahan; 5) membangun jiwa mandiri dan inovatif siswa yang berkarakter: jujur,bertanggungjawab, disiplin, peduli dan toleransi; dan 6) menumbuhkembangkan pola pikir teknologis dan estetis: cekatan, ekonomis dan praktis[3].

\section{Kesimpulan}

Hasil analisis menunjukkan bahwa guru-guru IPA SMP di Kabupaten Sijunjung masih belum professional dalam mengajarkan prakarya di sekolah. Hal ini disebabkan karena masih kurangnya penerapan sains/IPA dalam pembelajaran prakarya. Mata pelajaran prakarya memiliki empat aspek materi yaitu: kerajinan, rekayasa, budidaya, dan pengolahan. Aspek materi kerajinan lebih dominan diajarkan oleh guru IPA dalam mata pelajaran prakarya padahal aspek materi ini lebih tepat diajarkan oleh guru seni budaya/keterampilan. Selain itu, masih sedikitnya guru IPA yang mampu menyusun bahan ajar prakarya. Oleh karena itu, hasil analisis ini dapat dijadikan sebagai rujukan dalam rujukan dalam pelaksanaan kegiatan pendampingan sains terapan dalam pembelajaran prakarya sehingga kegiatan yang dilaksanakan sesuai dengan kebutuhan.

\section{Ucapan Terima Kasih}

Tulisan ini adalah bagian dari Hibah Program Kemitraan Masyarakat Tahun 2019 yang dibiayai oleh DIPA DRPM Kementerian Riset, Teknologi, dan Pendidikan Tinggi. Penulis mengucapkan terima kasih kepada Rektor UNP, Ketua LP2M UNP, dan MGMP IPA SMP Kabupaten Sijunjung.

\section{Pustaka}

[1] Soda Bottle Passive Hydroponics System. 2009.http://www.hydroponicssimplified.com

[2] Boslaugh S, P A Watters. Statistics in Nutshell. USA: O'Reilly Media, Inc, 2008.

[3] Kemendikbud. Model Silabus Mata Pelajaran Prakarya Sekolah Menengah Pertama/Madrasah Tsanawiyyah (SMP/MTs). Jakarta: Kementerian Pendidikan dan Kebudayaan, 2016.

[4] Renol Afrizon, Letmi Dwiridal. "Upaya Menumbuhkan Karakter Peduli Lingkungan melalui Kajian Konsep Fisika Pada Arsitektur Kearifan Lokal Budaya Sumatera Barat." Jurnal Eksakta Pendidikan Vol 1 Nomor 2, 2017: 9-16.

[5] Vijendra Sahare, Preet Jain. "Automated Hydroponic System using Psoc4 Prototyping Kit to Deliver Nutrients Solution Directly to Roots of Plants on Time Basis." International Journal of Advanced Research in Electrical, Electronics and Instrumentation, 2015: 87658770.

[6] Silvira Wahyuni, Ramli, Mahrizal. "Pengaruh Suhu Proses dan Lama Pengendapan terhadap Kualitas Biodiesel dari Minyak Jelantah." Jurnal Pillar of Physics Vol. 6, 2015: 33-40. 